\title{
Portraying Design Essence
}

\author{
Leona Chandra Kruse \\ University of Liechtenstein \\ leona.chandra@uni.li
}

\author{
Jeffrey V. Nickerson \\ Stevens Institute of Technology \\ jnickerson@stevens.edu
}

\begin{abstract}
Recent discourse in the Design Science Research community addresses the necessity to accumulate and reuse design knowledge. However, design methods are complex and so are the traditional ways to document design knowledge. Inspired by the high business and academic impact of Business Model Canvas, we argue that a single-page portrayal of nine design elements can help designers to capture design knowledge and eventually share it with other designers. This paper reports on our attempt to create, demonstrate, and evaluate an instance of such tools, one that we call the Portrait of Design Essence.
\end{abstract}

\section{Introduction}

"In order to make progress, one must leave the door to the unknown ajar - ajar only"

-Richard Feynman

Good design is expected to go beyond a single success story. Recent discourse on design, including information systems (IS) design, addresses the necessity to accumulate and reuse design knowledge. We can observe this inclination in various occasions and publications, from Journal of the Association of Information Systems' (JAIS) call for papers that are devoted to knowledge evolution and accumulation in Design Science Research (DSR) [1] to Management Information Systems Quarterly's (MISQ) editorial commentary on the diversity of DSR [2] and published empirical research on knowledge reuse for customization [3]. Given this tendency, a question immediately follows: in which form does design knowledge accumulate for reuse?

Several alternative forms have thus been put forward, including design patterns [4, 5], technological rules [6,7], and design principles or design theory $[8,9]$. However, these heuristics are often specific to particular design domains. Moreover, existing methods of documenting design are complex, perhaps overly so. In the field of software design an empirical study of Unified Modeling Language (UML) showed that most programmers don't use it.
[10]. Can we reduce the complexity by portraying the essence on a simple medium that allows for overview?

We can learn from the success story of Business Model Canvas (BMC). BMC was popularized by Osterwalder and Pigneur [11] as a simple instrument to assist entrepreneurs and managers alike in externalizing their ideas and formulating essential components of a business model on a single page. BMC consists of nine boxes that represent essential elements of a business model, such as value propositions and revenue streams. Ever since its introduction, BMC has been adopted by various organizations around the world and the book Business Model Generation [11] has been cited more than 5100 times (Google Scholar) and sold more than a million copies in 36 languages (alexosterwalder.com). JAIS has also published an article about the contribution of IS in designing business models with reference to BMC [12]. We can characterize the Business Model Canvas as a compression tool; it gets at the essence of the problem by reducing ideas into a one-page format. Other examples of one-page summaries include balanced score cards [13], concept maps [14], and strategy maps [11]. Moreover, BMC is a mnemonic: because there only nine elements to be addressed, these nine can be easily remembered. Indeed, many mnemonics involve between five and nine items, the capacity of short term memory [15]. The graphic form of a canvas reinforces its mnemonic quality: there is a place to put everything [e.g., 16].

Design activities and entrepreneurial activities indeed share striking similarities. Both activities are complex, creative, and generative, engage abductive reasoning, and bring into being new entities or - to follow the Schumpeterian spirit - new combinations of previously existing entities. The challenge of capturing the essence is shared among these activities as well - recall the notion of "core" value proposition in new venture design. If BMC's utility in business model generation and new venture design has been widely reported, then we can adapt its formal qualities to fit the specific context and the language of design.

In sum, we start with a design constraint: the tool we create will utilize a single page and will contain at most nine categories. That is, we want to create something like $\mathrm{BMC}$, something that is both 
mnemonic and compressive. We want it to apply to design in general and in particular to the design of systems. In this paper, given this self-imposed format constraint, we address one specific generative question: how can we create a tool that captures the essence of a design?

Our contributions are threefold. First, we characterize the essence of design as a mixture of nine elements, extracted from the design, systems, information systems, and software engineering literature. Second, we create a portrait of design essence and conducted a preliminary evaluation of the artifact. Third, the portrait of design essence can be used as a tool to support the planning stage of design as well as to document the lessons learned in a design process.

\section{Background}

\subsection{Design Knowledge Reuse}

The notion of design knowledge is in itself a subject worthy of further elaboration. We can clarify the notion by employing widely used classification for (design) knowledge. Garud [17], for instance, drew a distinction between "know-how", "know-why", and "know-what" that respectively represent procedural, causal, and declarative knowledge. Others have an established tradition of describing artifacts with regards to their form or structure, function, and behavior [18-20]. Both ways are aimed towards providing other designers with sufficient knowledge to rebuilt similar artifacts - to codify design knowledge.

Codified design knowledge can be represented in various forms such as design patterns [4, 5], technological rules [6, 7], analysis patterns [8], and design principles $[9,10]$. We assume that design knowledge is codified for the purpose of reuse [see 21]. Even though reusing is sometimes associated with repetition, reuse has been observed in contexts that strive toward innovation [22] and customization [3].

Knowledge reuse can be facilitated by enhancing the reusability attribute of the design knowledge itself (e.g., capturing and documenting knowledge) or making the knowledge sharing among designers easier (e.g., developing and maintaining good repositories for knowledge dissemination) [23]. Unfortunately, to quote Johnson [24], "with a few exceptions [...] design guidelines are provided as simple lists of design edicts with little or no rationale or background". This may be expected to affect the way such knowledge is interpreted and eventually reused.

PDE is intended to facilitate knowledge reuse through both strategies proposed by Markus [23]: a. PDE captures and documents design knowledge in both textual and graphical form.

b. By drawing inspiration from BMC, PDE portrays design essence on a single page that is easy to share among designers.

\subsection{Business Model Canvas}

According to Osterwalder and Pigneur [12], business model is an exemplar of strategic objects for managers and entrepreneurs that improves strategic discussions and enhances decision making. They adopted the approach of "managing as designing" [25] in business model design. A business model is defined as "a conceptual tool containing a set of objects, concepts and their relationships with the objective to express the business logic of a specific firm" [26].

In their attempt to provide a simple instrument to assist entrepreneurs and managers in designing and analyzing business models, BMC was introduced [26]. Subsequently, the book "Business Model Generation" [11] was published; it articulates the general idea of a business model and of particular knowledge on each of its building blocks. This book has been translated into 36 languages and sold more than a million copies (alexosterwalder.com), and has been cited more than 5100 times (Google Scholar). The nine building blocks of BMC are: (1) key partners, (2) key activities, (3) key resources, (4) value propositions, (5) customer relationships, (6) channels, (7) customer segments, (8) cost structure, and (9) revenue streams.

Learning from BMC's success story, we have identified three key points that we use as an inspiration for PDE:

a. Putting together all elements on a single page provides a good overview.

b. Visualization in textual and graphical forms assist understanding, communication, and sharing among relevant stakeholders.

c. Even complex units can be simplified and their simplified representations are still meaningful.

\subsection{Complexity Reduction}

Design methods are complex, perhaps overly so. In the field of software design an empirical study of the Unified Modeling Language (UML) showed that most programmers don't use it. Moreover, when they do use it, it is often done after the fact to please management, rather than as a design tool [10]. Can something simpler be used? In other words, can the complexity of design processes be reduced? There is a long history of complexity reduction in systems design [e.g., 27], 
including a seminal work on Socio-Technical Systems Design by Emery and Trist [28].

There are a variety of techniques for reducing complexity. When distances can be computed, multidimensional scaling can be used (see Kruskal [29]). Even in the absence of distance measures, nonparametric methods such as compression can be used on digital data. But in everyday conversation we rely mainly on summarization heuristics to reduce dimensionality. Techniques such as balanced scorecards and the BMC work in part because they reduce a complex task into a small number of subtasks that are to be represented on a single page. The single page format forces compression. In other words, regardless of the actual questions asked, the one page format may both reduce the complexity of the overall task and force compression.

\section{Method}

We used the inspiration from Peffers, et al.'s [30] DSR approach in designing and evaluating the Portrait of Design Essence (PDE). This approach consists of six stages: identify problem and motivate, define objectives of a solution, design and development, demonstration, evaluation, and communication.

\subsection{Problem and Motivation}

Design is complex and so are available design methods. Petre's [10] study suggested that UML is often used after the fact to please management, rather than as a design tool. Knowledge sharing among designers becomes more challenging as the complexity increases and long documentation makes it difficult for designers to formulate an overview. A similar problematization has been reported [26] to justify the need for BMC. Now that BMC has been widely adopted and respected, we can apply a similar approach to a tool for both design and design knowledge.

\subsection{Objectives of PDE}

Our objectives are (1) to characterize the essence of design as a mixture of elements (2) to create a tool that captures and compresses the essence of early design conversation, (3) that is simple and easy to use, and supports the accumulation of design knowledge.

\subsection{Designing PDE}

We used a heuristic method to construct a set of elements to include on a one sheet design essence. We chose general design techniques that apply to not only software design but also other areas of design (see Section 4).

Inspired by the high business and academic impact of BMC, we portrayed nine elements of design essence in nine boxes of different shape according to the expected space requirement to represent each element. PDE is two-sided. One side portrays empty boxes, while the other side provides triggering statements to guide designers through the boxes.

\subsection{Evaluating PDE}

We asked two expert designers with five and twelve years of professional experience to try out PDE. The first participant is a professional information systems designer who works at a multinational financial institution. The second participant, on the other hand, is a professional embedded-systems engineer who specializes in sensor, chip, and circuit design. Given their diversity in domain knowledge, professional experience, and design specialization, they provided us with valuable feedbacks to improve PDE.

The participants were given PDE, an instruction sheet, and a questionnaire. We asked them to recall a design project they have recently completed or simply reflect upon a design project they are currently working on and fill out PDE. Furthermore, we specifically requested them to note down any difficulty and ambiguity to support recollection when answering the questionnaire. Our questionnaire consists of open-ended questions that are intended to gather their positive and negative experience when using PDE.

\section{A Portrait of Design Essence}

Let us begin with a brief clarification on the term "design essence". According to Oxford dictionary, the term "essence" is originated from Latin essentia that literally means "be" - therefore, essence is "the intrinsic nature or indispensable quality of something, especially something abstract, which determines its character". This definition shares the sentiment of essentialism - "to be essentialist is to treat objects as if they have essences or underlying natures that make them the thing that they are, and to treat them as if they have properties that result from these essences" [31]. But what is the implication of essence in reuse?

Barrett [31] further gave an example of reusing or "copying" the essence of a chair. In his argument, there are several functional features that are expected to be preserved across instances of chair. However, those instances of chair may vary along several dimensions (e.g., compare beanbag and armchair) without compromising the intended functionality of a 
chair (e.g., for people to sit on). He explained that such degrees of freedom in design expression are indeed expected from designers, representing a mixture of novelty and reuse in creativity and innovation.

Barrett's argument perfectly outlines what we intend our Portrait of Design Essence to be. PDE accommodates novelty and reuse at the same time. It captures the aspects that are expected to be preserved across the class of design, while encourages designers to embed unique propositions into their designs by either generating new ideas or simply modifying and combining previously implemented ones - it captures design essence indeed.

PDE incorporates nine elements that represent design essence which we drew from general design techniques that apply to not only software design but also other areas of design. In fact, the same method has been put to use by Johnson [24] when he observed that "all of these sets of user-interface design guidelines are quite similar if we ignore differences in wording, emphasis, and the state of computer technology when each set was written". He gave an example of correspondence between Shneiderman \& Plaisant's [32] rule to "permit easy reversal of actions" and Nielsen-Molich's [33] rule to "help users recognize, diagnose, and recover from errors". The same can be said for the elements of PDE. To give an example, "choice points" could well have been named "conflicting goals" or "decision points" since they convey the same essence; however, we are bound to select one name for the sake of clarity and coherence.

Each PDE element is depicted in the following structure: Name - Description - Representation Trigger. Name is self-explanatory. Description offers justification and summary of what each element is about. Representation indicates the form each element is expected to be documented on PDE (i.e., textual description or diagram). Finally, Trigger articulates the statements written to provide designers with a sense of direction when filling out PDE. PDE with and without triggering statements are presented in Appendix 1 and Appendix 2 respectively.

\section{Element \#1: Scenarios}

Description: Scenarios are narratives. Carroll's research on scenarios suggests two different types of scenarios, problem and solution. The problem scenario tells the story of something currently happening that is not satisfactory. The solution scenario reimagines the communication between actors after the system is complete [34].

To be represented as: textual description.

Triggering statements: (1) provide a specific narrative about a current problem situation; (2) provide a specific narrative in the future when the design has been realized.

\section{Element \#2: Actors}

Description: Actors are roles adopted by external entities when interacting with the design [35]. The external entities may be human users or non-human agents that interact directly with the design. Actors can be enumerated by listing the set of nouns that occur in the solution scenario.

To be represented as: textual description.

Triggering statement: list all nouns in the scenarios.

\section{Element \#3: Dynamics}

Description: Design products are expected to demonstrate certain behaviors. This element describes how the behaviors unfold over time. In particular, dynamics can portray the interaction between actors over time, using sequence diagrams. Sequence diagrams are part of UML [36], and simplified versions of them can be quickly taught.

To be represented as: diagram.

Triggering statement: draw a sequence diagrams showing the communication between actors.

\section{Element \#4: Structures}

Description: Structure is about how the pieces are connected. This element shows relationships between components and subsystems of a design.

To be represented as: diagram.

Triggering statement: show all relations between components and subsystems.

\section{Element \#5: Preexisting Components}

Description: Few designs are realized by starting from scratch. Instead, designs themselves are reused; this is described as reuse for innovation [22] - a new design may be the result of combining and refining already existing components.

To be represented as: textual description

Triggering statement: list all preexisting designs or implementations that can be applied to the scenarios.

\section{Element \#6: Constraints}

Description: Design problems can often be viewed as constraint satisfaction problems. Constraints have been shown to be valuable in design: they can help reduce search space, and they can reveal the structure of the design space. Constraints can be documented in a textual way, indicating ranges for critical values, or indicating relationships between actors in the system. To be represented as: textual description

Triggering statement: list all assumptions about resources and restrictions.

\section{Element \#7: Choice Points}

Description: Design problems often have multiple conflicting goals and satisfying these design goals calls for tradeoffs [24]. Writing down these conflicting 
goals helps in making decisions about the right balance between these competing goals.

To be represented as: textual description.

Triggering statement: list the sequence of decisions that need to be made (e.g., in software design one decision could be about platform, while in product design material choice is usually decisive).

\section{Element \#8: Evaluation Criteria}

Description: Design has often been described as conversation that shuttles between design space and evaluation space $[37,38]$. The criteria are dimensions along which a design can be evaluated.

To be represented as: textual description.

Triggering statements: (1) list criteria that will be used to judge the design; (2) indicate if there are priorities.

\section{Element \#9: Design Themes}

Description: Design themes summarize PDE in brief sentences, so that designers can easily identify whether a PDE is relevant to their current design situation. As reuse can be promoted by either enhancing the reusability attribute of the design knowledge or making the knowledge sharing among designers easier [23], quick identification of general approaches/themes/goals of a PDE aids knowledge sharing.

To be represented as: textual description.

Triggering statement: describe the overall approach or theme or goal. What did you pay particular attention on?

\section{Evaluation of PDE}

\subsection{Participants' General Evaluation}

We employed two criteria in general evaluation of PDE: (1) perceived benefits of PDE and (2) experienced ambiguity or difficulty while using PDE. We gathered participants' responses to these evaluation criteria, which they reported after completing PDE. Several benefits were mentioned by participants in the following quotes:

\section{\# D 1: Information Systems Designer}

- Good overview: everything on one page.

- Given structure, easy to find the relevant points.

\section{\# D 2: Embedded Systems Designer}

- It enables me to think in broader scope than what I thought before. I only thought of the technical aspect. After trying to write the scenario, I found out that I do need to think the value proposition of my design and its relevance to the targeted user of the device.

- I thought this sheet would be helpful to think on another aspect of the project and will help to brainstorm with my colleague.

- I think filling simple sheet like this will save time instead of writing comprehensive report and enable me to do initial evaluation of the project. But I think in the end we will still need to write comprehensive report.

On the other hand, participants also described several points for improvement in the following quotes:

\section{\# D 1}

- Structure probably not suitable for complex projects (not scalable), e.g. sequence diagrams can easily become huge and complex.

- For bigger projects the page may become too big for printing, or you have to divide the project into smaller parts.

\# D 2

- Particularly in design theme section because I am not sure what I should fill. I am not familiar with the term 'design theme', 'actor' or 'dynamics'. Usually in project documents, the section name would be 'goal', 'problem formulation', 'experiments', or 'methods'.

\subsection{Participants' PDE Contents}

We also analyzed the contents of completed PDEs to find out (1) whether each box has been filled out according to its intended domain and (2) contents that are unintended or surprising.

\section{\# D 1: Designing Car Leasing Application}

Our observations (cf. Figure 1):

- D1 has filled out practically all boxes with the expected elements.

- Drawing diagrams did not seem to cause any difficulty for D1.

- The reported design theme - "in leasing application, add car details, e.g. factory supplied accessories" - summarizes the lessons learned from the design project.

- The reported choice point - "architecture was given" - indicates the limited or absence of choice points in routine of improvement design projects. 


\section{\# D 2: Designing Smart Home}

Our observations (cf. Figure 2):

- D2 has filled out practically all boxes with the expected elements.

- Drawing diagrams did not seem to cause any difficulty for D2.

- As for design themes, D2 filled the box with a brief description of project goal, purpose of device, and the main concerns addressed by the project.

- D2 wrote down the following actors: "home, office, building maintenance, electricity costs, smart home device, wall outlet, smart outlet". While most of the actors are indeed relevant actors, building maintenance and electricity seem to represent components other than actors.

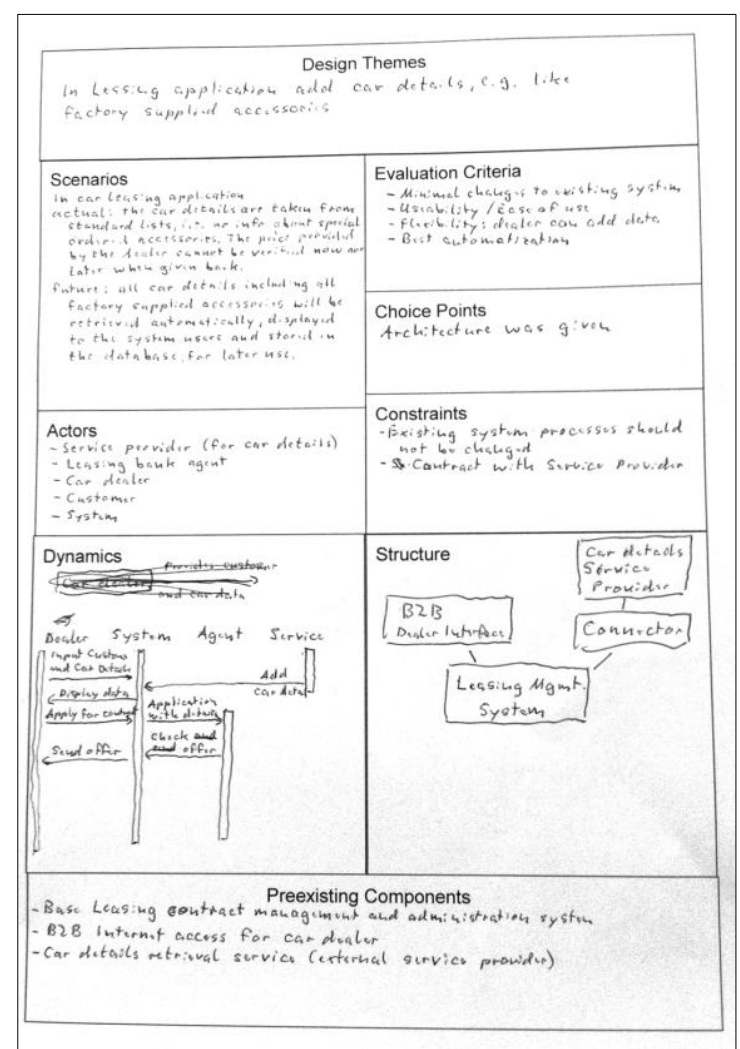

Figure 1. PDE completed by D1

Based on our preliminary evaluation, the following points are worthy of consideration when creating an improved version of PDE for future evaluation:

- More clarity is required for Design Themes and Choice Points that can be attained by providing examples for each element.

- A second triggering statement can be useful to distinguish actors from other components: (1) List all nouns in the scenarios, (2) Indicate the nouns that have direct interaction with the design. These are the actors.

- Some of the elements should be extendable (i.e., those that ask for diagrams). Possible extension: folded paper and pull tab for printed PDE, jigsaw puzzle style for highly complex design, "click and enlarge" function for digital PDE.

- Consider using different digital platforms for PDE and evaluate the utility in each format.

All things considered, PDE fulfills our objectives - at least in the case of our participating designers. Three themes recurred among designers' description of what they perceived to be the benefits of PDE. First, PDE provides a good overview of the design scope. Second, PDE supports communication among designers. Third, PDE saves time in recognition of relevant design knowledge.

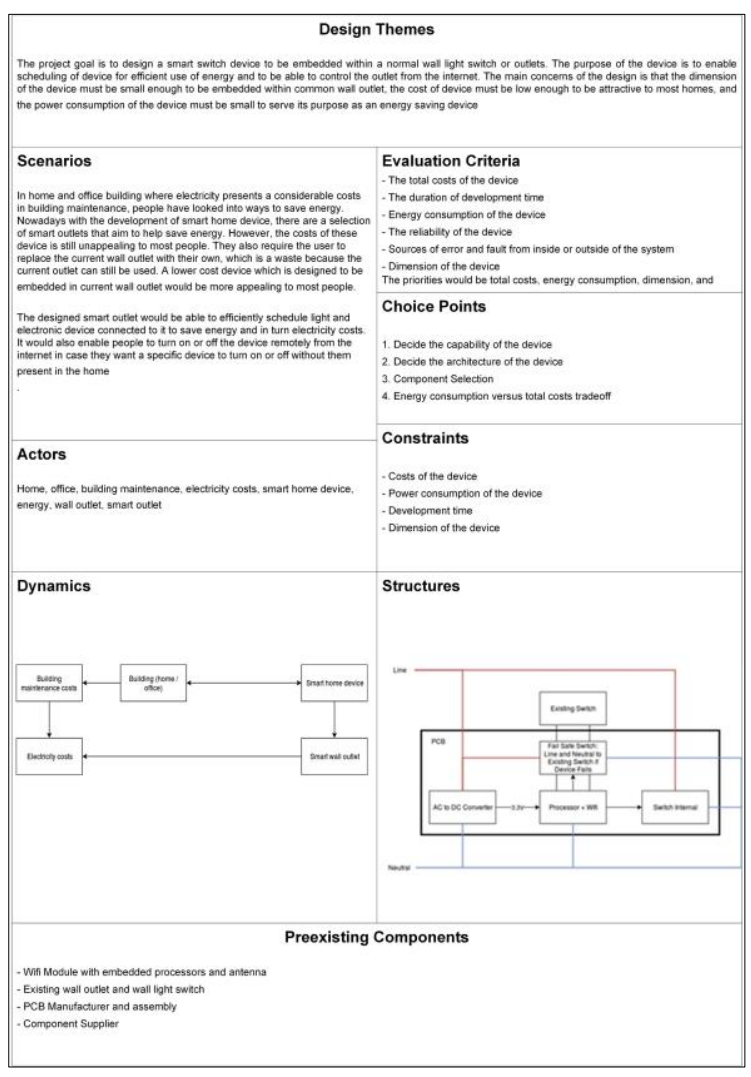

Figure 2. PDE completed by D2

\section{Discussion}

\subsection{PDE Use at Different Design Stages}

The importance of separating the essential aspects of design and design knowledge from the arbitrary 
ones was asserted by Gregor, et al. [39], where such knowledge can be generated upon reflection and abstraction of a design artifact. In their framework, design knowledge of design essence is captured at the later stage of design. While the same can intuitively be applied to the case of capturing design essence in PDE, we expect PDE utility to stretch across different stages of design [cf. 41].

At the early stage of design, PDE captures the essence of early design conversation between two or more designers as well as between a designer and herself. Since design is an iterative process, PDE may evolve over time. We may even gain deeper understanding about a design project (such as its critical decisions) by analyzing the evolution of PDE. At the later stage of design, PDE captures the essence of the final design - it documents the essential aspects of design in a simple way that promotes knowledge reuse. Summing up, there are more than one way to utilize PDE to cater to different needs.

\subsection{Future Evaluation}

We started with a constraint of nine categories of information. Ideally, we should be able to find out through evaluation whether these are the right nine categories. Generally speaking, the number of possible choices of nine categories is practically infinite. We proceeded by starting with the nine choices described here, motivated by previous empirical studies. We then can ask "By substituting one outside category for one chosen category, do we see changes in design performance?". This question allows for a gradual and systematic search through the design space.

Design performance is perhaps another fuzzy term to evaluate. We argue that design performance can be evaluated on two levels. First, the quality of design concepts. Second, the quality of the realized design concepts. We envision quality measurement to be delegated to a panel where expert designers and lead users sit together to express their opinion both qualitatively and quantitatively. Empirical findings indeed suggest that designers work equally well in teams of one (i.e., loners) as well as in teams of several [40]. However, it is still interesting to observe team dynamics when utilizing PDE.

In future research, we will take the feedback we have received and perform $\mathrm{A} / \mathrm{B}$ experiments in which designers are placed into control and treatment conditions in order to better understand the dimensions and the impacts of alternative dimensions. Candidate alternative dimensions will be constructed after analyzing data collected as previous versions are used in practice. Thus, future versions may represent improvements, a result of empirical research.

\section{Concluding Remarks}

We began this paper by asking: how can we create a tool that captures the essence of a design? We addressed this question by (1) characterizing the essence of design as a mixture of nine elements and (2) creating PDE that captures the essence of early design conversation and supports knowledge sharing. The preliminary evaluation suggests that designers found PDE to provide good overview, support communication, and save time in finding relevant design knowledge. Our ongoing and further research follows the previously discussed improvement and evaluation strategies. As Feynman has famously said, "in order to make progress, one must leave the door to the unknown ajar - ajar only." He did not say to leave the door wide open to the unknown - perhaps because progress means a harmony between novelty and reuse. We hope that this research will make a contribution in accumulating and reusing design knowledge.

\section{Acknowledgements}

This material is based upon work supported by the Research Fund of the University of Liechtenstein and the National Science Foundation under grants 1422066, 1442840, and 1717473.

\section{References}

[1] Vom Brocke, J., A.R. Hevner, A. Maedche, and R. Winter, "Call for Papers Special Issue: Accumulation and Evolution of Knowledge in Design Science Research".

[2] Rai, A., "Editor's Comments: Diversity of Design Science Research", Management Information Systems Quarterly, 41(1), 2017, pp. iii-xviii.

[3] Kyriakou, H., J.V. Nickerson, and G. Sabnis, "Knowledge Reuse for Customization: Metamodels in an Open Design Community for 3D Printing", MIS Quarterly, 41(1), 2017, pp. 315-332.

[4] Borchers, J., "A Pattern Approach to Interaction Design AI \& Society Journal of Human-Centred Systems and Machine Intelligence, 15, 359-376".

[5] Denning, P. and P. Dargan, "Action-centered design", Bringing design to software, 1996, pp. 105-119.

[6] van Aken, J.E., "Management research based on the paradigm of the design sciences: the quest for fieldtested and grounded technological rules", Journal of Management Studies, 41(2), 2004, pp. 219-246.

[7] Bunge, M., Philosophy of science: from problem to theory, Transaction Publishers, 1998.

[8] Denning, P.J.: "Great principles of computing", Communications of the ACM 46, 15-20 (2003) 
[9] Sein, M.K., O. Henfridsson, S. Purao, M. Rossi, and R. Lindgren, “Action Design Research", MIS Quarterly, 35(1), 2011, pp. 37-56.

[10] Petre, M., "UML in Practice", Proceedings of the 2013 International Conference on Software Engineering, 2013, pp. 722 - 731.

[11] Osterwalder, A. and Y. Pigneur, Business model generation: a handbook for visionaries, game changers, and challengers, John Wiley \& Sons, 2010.

[12] Osterwalder, A. and Y. Pigneur, "Designing business models and similar strategic objects: the contribution of IS", Journal of the Association for Information Systems, 14(5), 2012, p. 3.

[13] Kaplan, R.S. and D.P. Norton, The balanced scorecard: translating strategy into action, Harvard Business Press, 1996.

[14] Novak, J.D., Learning, creating, and using knowledge: Concept maps as facilitative tools in schools and corporations, Routledge, 2010.

[15] Miller, G.A., "The magical number seven, plus or minus two: some limits on our capacity for processing information", Psychological review, 63(2), 1956, p. 81.

[16] Yates, F.A., The art of memory, Random House, 1992.

[17] Garud, R., "On the distinction between know-how, know-what, and know-why", Advances in strategic management, 14, 1997, pp. 81-102.

[18] Gero, J.S., "Design prototypes: a knowledge representation schema for design", AI magazine, 11(4), 1990, p. 26.

[19] Gero, J.S. and U. Kannengiesser, "The situated function-behaviour-structure framework", Design Studies, 25(4), 2004, pp. 373-391.

[20] Gero, J.S. and T. Mc Neill, "An approach to the analysis of design protocols", Design Studies, 19(1), 1998, pp. 21-61.

[21] Melton, H., "On the usage and usefulness of OO design principles", Companion to the 21st ACM SIGPLAN Symposium on Object-oriented Programming Systems, 2006, pp. 770 - 771.

[22] Majchrzak, A., L.P. Cooper, and O.E. Neece, "Knowledge reuse for innovation", Management science, 50(2), 2004, pp. 174-188.

[23] Markus, L.M., "Toward a theory of knowledge reuse: Types of knowledge reuse situations and factors in reuse success", Journal of management information systems, 18(1), 2001, pp. 57-93.

[24] Johnson, J., Designing with the mind in mind: simple guide to understanding user interface design guidelines, Elsevier, 2013.

[25] Boland Jr, R.J., F. Collopy, K. Lyytinen, and Y. Yoo, "Managing as designing: lessons for organization leaders from the design practice of Frank O. Gehry", Design Issues, 24(1), 2008, pp. 10-25.

[26] Osterwalder, A., Y. Pigneur, and C.L. Tucci, "Clarifying business models: Origins, present, and future of the concept", Communications of the association for Information Systems, 16(1), 2005, p. 1.

[27] McCabe, T.J. and Butler, C.W. "Design complexity measurement and testing", Communications of the ACM 32 (12), (1989), pp. 1415 - 1423.

[28] Emery, F.E. and E.L. Trist, Towards a social ecology: Contextual appreciations of the future in the present, Springer Science \& Business Media, 2012.

[29] Kruskal, J.B., "Multidimensional scaling by optimizing goodness of fit to a nonmetric hypothesis", Psychometrika, 29(1), 1964, pp. 1-27.

[30] Peffers, K., T. Tuunanen, M.A. Rothenberger, and S. Chatterjee, "A design science research methodology for information systems research", Journal of management information systems, 24(3), 2007, pp. 45-77.

[31] Barrett, H.C., "On the functional orgins of essentialism”, Mind \& Society, 2(1), 2001, pp. 1-30.

[32] Shneiderman, Ben \& Plaisant, Catherine, Designing the user interface: strategies for effective human-computer interaction, Pearson Education India, 2010.

[33] Nielsen, J. and R. Molich, Heuristic evaluation of user interfaces, ACM, 1990.

[34] Carroll, J.M., "Five reasons for scenario-based design", Interacting with computers, 13(1), 2000, pp. 43-60.

[35] Rumbaugh, J., M. Blaha, W. Premerlani, F. Eddy, and W.E. Lorensen, Object-oriented modeling and design, Prentice-Hall,1991.

[36] Rumbaugh, J., I. Jacobson, and G. Booch, Unified modeling language reference manual, Pearson Higher Education, 2004.

[37] Nickerson, J.V. and L.L. Yu, "Going Meta: Design Space and Evaluation Space in Software Design", in Software Designers in Action. 2014. CRC Press.

[38] MacLean, A., R.M. Young, and T.P. Moran, "Design rationale: the argument behind the artifact", roceedings of the SIGCHI Conference on Human Factors in Computing Systems, 1989, pp. 247-252

[39] Gregor, S., Müller, O., and Seidel, S.," Reflection, Abstraction, and Theorizing in Design and Development Research", Proceedings of European Conference on Information Systems, 2013.

[40] Goldschmidt, G., "The designer as a team of one", Design Studies, 16(2), 1995, pp. 189-209.

[41] vom Brocke, J., Fettke, P., Gau, M., Houy, C., Maedche, A., Morana, S., \& Seidel, S., "Tool-Support for Design Science Research: Design Principles and Instantiation", 2017. 


\section{Appendix 1: The Portrait of Design Essence with Triggering Statements}

\begin{tabular}{|c|c|}
\hline \multicolumn{2}{|c|}{$\begin{array}{l}\text { Design Themes } \\
\text { Describe the overall approaches or themes or goals. What did you pay particular attention on? }\end{array}$} \\
\hline \multirow{3}{*}{$\begin{array}{l}\text { Scenarios } \\
\text { Provide a specific narrative about a current problem } \\
\text { situation. } \\
\text { Provide a specific narrative in the future when the design has } \\
\text { been realized. }\end{array}$} & $\begin{array}{l}\text { Evaluation Criteria } \\
\text { List criteria that will be used to judge the design. } \\
\text { Indicate if there are priorities. }\end{array}$ \\
\hline & $\begin{array}{l}\text { Choice Points } \\
\text { List the sequence of decisions that need to be made. (e.g., in } \\
\text { software design one decision could be about platform, while } \\
\text { in product design material choice is usually decisive). }\end{array}$ \\
\hline & Constraints \\
\hline $\begin{array}{l}\text { Actors } \\
\text { List all nouns in the scenarios. }\end{array}$ & List all assumptions about resources and restrictions. \\
\hline $\begin{array}{l}\text { Dynamics } \\
\text { Draw a sequence diagram showing the communication } \\
\text { between actors. }\end{array}$ & $\begin{array}{l}\text { Structures } \\
\text { Draw all relations between components and subsystems. }\end{array}$ \\
\hline \multicolumn{2}{|c|}{ Preexisting Components } \\
\hline
\end{tabular}


Appendix 2: The Portrait of Design Essence without Triggering Statements

\begin{tabular}{|c|c|}
\hline \multicolumn{2}{|c|}{ Design Themes } \\
\hline \multirow[t]{3}{*}{ Scenarios } & Evaluation Criteria \\
\hline & Choice Points \\
\hline & Constraints \\
\hline Dynamics & Structures \\
\hline \multicolumn{2}{|c|}{ Preexisting Components } \\
\hline
\end{tabular}

